\title{
Serum human endothelial cell-specific molecule-I (endocan) and vascular endothelial growth factor in cirrhotic HCV patients with hepatocellular carcinoma as predictors of mortality
}

This article was published in the following Dove Press journal: Clinical and Experimental Gastroenterology

\author{
Anas A Youssef' \\ Hisham A Issa' \\ Maha Z Omar² \\ Eman G Behiry' \\ Asmaa A Elfallah' \\ Ali Hasaneen ${ }^{3}$ \\ Mohamed Darwish ${ }^{3}$ \\ Dalia B Ibrahim ${ }^{4}$ \\ 'Department of Clinical and Chemical \\ Pathology, Faculty of Medicine, Benha \\ University, Benha, Egypt; ${ }^{2}$ Department \\ of Hepatology, Gastroenterology \\ \& Infectious Diseases, Faculty of \\ Medicine, Benha University, Benha, \\ Egypt; ${ }^{3}$ Department of Internal \\ Medicine, Faculty of Medicine, Benha \\ University, Benha, Egypt; ${ }^{4}$ Department \\ of Clinical and Chemical Pathology, Al \\ Tahrir Hospital, Giza, Egypt
}

Objectives: The aim of this study was to assess serum levels of endocan \& VEGF in patients with hepatitis $\mathrm{C}$ virus-related HCC and their diagnostic and predictive value of mortality.

Methods: A total of 195 patients with $\mathrm{CHC}$ were subdivided into the following two groups: $105 \mathrm{HCV}$ cirrhotic patients with HCC and $90 \mathrm{HCV}$ cirrhotic patients without HCC. Sixty apparently healthy subjects served as the control group. The serum VEGF and endocan were assessed by ELISA.

Results: The mean serum endocan level was $4257.6 \pm 847.6 \mathrm{pg} / \mathrm{mL}$ in HCC patients, compared to $2099.2 \pm 459.6 \mathrm{pg} / \mathrm{mL}$ in liver cirrhosis patients without HCC. VEGF levels in the HCC group were non-significantly higher than those of the non-HCC group, and control group. Endocan at cut-off value $2967 \mathrm{pg} / \mathrm{ml}$ had higher sensitivity and higher specificity in diagnosis of HCC than AFP and VEGF. The median follow up period was 9 months, survival curve analysis was done in HCC group and showed that probability of survival among HCC group with higher levels of VEGF and endocan were significantly lower than that patients with low levels. In HCC patients, elevated serum endocan levels were significantly associated with poor hepatic functions and a greater number and size of tumours. Multivariate analysis showed that serum endocan levels ( $\geq 4000 \mathrm{pg} / \mathrm{ml}$ ), as well as elevated serum fetoprotein $(>100 \mathrm{ng} / \mathrm{dl}$ ), were independent prognostic biomarkers for mortality.

Conclusion: Endocan may be a useful diagnostic marker for HCC and a good predictor of mortality, especially when combined with AFP and VEGF.

Keywords: hepatocellular carcinoma, endocan, VEGF, AFP

\section{Introduction}

The major risk factor in the development of hepatocellular carcinoma (HCC) is cirrhosis of the liver. Cirrhosis particularly when related to viral hepatitis is the most notable risk factor for HCC and is found in nearly $80-90 \%$ of cases. ${ }^{1}$

$\mathrm{HCC}$ is the sixth most common cancer worldwide and the third most common cause of death. In Egypt, liver cancer forms $1.68 \%$ of the total malignancies. HCC constitutes $70.48 \%$ of all liver tumors among Egyptians and represents the main complication of cirrhosis. ${ }^{2}$

The gold standard for diagnosis is through liver biopsy and histopathological examination. This is an invasive and expensive procedure, a source of patient anxiety, with the danger of acquainting contamination with the patient or, seeding the tumor
Correspondence: Eman G Behiry Department of Clinical and Chemical Pathology, Faculty of Medicine, Benha University, PO Box 130I5, Benha, Egypt Tel +201006216116

Email emangamal24@yahoo.com 
along the biopsy tract.3 Therefore, new serological markers with adequate affectability and specificity are expected to recognize HCC amid reconnaissance on account of ultrasound antagonism. Angiogenesis is accepted to assume a noteworthy job in the advancement and progression of $\mathrm{HCC}$; it is a confused procedure directed by numerous angiogenic factors, including vascular endothelial growth factor (VEGF) and endocan. ${ }^{4}$

Endocan, or endothelial-specific molecule-1, is a soluble proteoglycan of $50 \mathrm{kDa}$ that is synthesized and secreted by activated vascular endothelial cells, including a tumor endothelial cells..$^{5}$ Endocan production is upregulated by angiogenic factors and inflammatory cytokines, such as tumor necrosis factor and interleukin-1 $\beta .^{6}$ In experimental studies, endocan has been found to induce tumor formation and to be closely associated with the conversion of dormant tumors into fast-growing angiogenic tumors. ${ }^{7}$

VEGF is a standout amongst the most critical angiogenesis controllers what's more, has been recommended as a helpful natural marker of tumor intrusiveness and prognosis of $\mathrm{HCC}^{8}$ It advances endothelial multiplication and increments vascular penetrability by binding to particular receptors in endothelial cells. ${ }^{9}$ VEGF additionally associated with the improvement and movement of lung, gastrointestinal, and breast cancers. ${ }^{10}$ This investigation meant to evaluate the serum level of endocan and VEGF in HCV-related HCC patients and to survey their role as indicators of mortality.

\section{Subjects and methods Subjects}

This prospective study was conducted on 195 patients attending Department of Hepatology, Gastroenterology, and Infectious Diseases and Department of Internal Medicine at Benha University Hospitals in addition to 60 apparently healthy subjects served as control group from June 2016 to March 2018, Laboratory work was carried out in the Department of Clinical and Chemical Pathology, Benha University. Subjects were classified into the following three groups:

- Group (I): $105 \mathrm{HCV}$ cirrhotic patients with HCC.

- Group (II): $90 \mathrm{HCV}$ cirrhotic patients without HCC

- Group (III): 60 apparently healthy subjects serving as control group.

Diagnosis of cirrhosis was based on the clinical, laboratory, and imaging criteria, and diagnosis of $\mathrm{HCV}$ was based on the $\mathrm{HCV} \mathrm{Ab}$ positive $>6$ months.

\section{Ethical approval}

This study protocol was approved by the ethical review board of Benha University. Written informed consent was obtained from each patient included in the study. The study protocol conforms to the ethical guidelines of the 1975 Declaration of Helsinki.

Patients aged $<18$ years, with liver cirrhosis due to $\mathrm{HCV}$ infection and HCC (diagnosed by elevated $\alpha$-fetoprotein [AFP], US criteria and confirmed by Triphasic abdominal CT without contrast), were enrolled in this study while patients aged $>18$ years, with liver cirrhosis due to HBV infection, extrahepatic metastasis, any other tumor than HCC, and with portal vein thrombosis were excluded.

\section{Methods}

All participants were subjected to the following:

1. Full history taking and thorough clinical examination.

2. Laboratory investigation including

Sampling: $6 \mathrm{~mL}$ of venous blood was drawn under aseptic conditions and distributed as follows:

1. One milliliter of whole blood was taken in an EDTA vacutainer (violet cap) and mixed gently. This sample was used to measure the complete blood count (CBC).

2. Five milliliters of blood was taken in plain test tubes without anticoagulant (red cap) and left until coagulation. After coagulation, the samples were centrifuged at 1,500 rpm for 15 minutes. The separated serum was used for the assay of liver function test (alanine aminotransferase [ALT], aspartate aminotransferase [AST], ALP, bilirubin, prothrombin time [PT], and albumin) and viral markers. The rest was stored at $-20^{\circ} \mathrm{C}$ until the assay of endocan, VEGF, and AFP.

Laboratory investigation

1. $\mathrm{CBC}$ : $\mathrm{CBC}$ was carried out for all samples using Sysmex KX-21N (Sysmex Corporation, New York, NY, USA) for red blood cell (RBC) count, hemoglobin level, hematocrit value, white blood cell (WBC) count (total and differential), and platelet count.

2. Biochemical liver tests: ALT and AST were assessed by the enzymatic rate method. Serum bilirubin (total and direct) was assessed by the Jendrassik and Grof method. Albumin was assessed by the modified bromocresol green colorimetric method. ALP was assessed by the kinetic determination using the A15 instrument (BioSystems, Barcelona, Spain). 
3. Viral markers: HCV Ab and HBs Ag were assessed by the third-generation ELISA.

4. AFP (ng/dL): the serum AFP was measured by ELISA technique using commercially available immunometric assays (Monobind Inc., Lake Forest, CA, USA) with lower limit of detection $(1.8 \mathrm{ng} / \mathrm{mL})$ and normal reference range $(2-10.9 \mathrm{ng} / \mathrm{mL})$.

5. Serum level of endocan: The serum endocan was measured by ELISA sandwich technique (Lot no 201610; Sunred Bio Company, Shanghai, China) with a lower limit of detection (7.50 ng/L) obtained as per the manufacturer's instructions and assay range (8-2,000 ng/L).

6. Serum VEGF: The serum VEGF was measured by ELISA sandwich technique (Lot no 201411; Sunred Bio Company) with a lower limit of detection (18.827 ng/L) obtained as per the manufacturer's instructions and assay range (20-6,000 ng/L).

3. Imaging modalities such as

1. Pelvic abdominal U/S: this was used to detect cirrhosis criteria, HCC (number-size-site). Portal V. diameter.

2. Abdominal tri-phasic CT with contrast: This was used to confirm the diagnosis of $\mathrm{HCC}$ (the new guidelines define the typical appearance of HCC on imaging as arterial-phase hypervascularity and portal, venous, or delayed-phase washout). ${ }^{11}$

4. The severity of liver disease was assessed by the ChildPugh score $^{12}$ and the Model for End-stage Liver Disease (MELD) score. ${ }^{13}$

5. The stage of a tumor was assessed by the Okuda staging system. ${ }^{14}$

\section{Statistical analyses}

Data were analyzed using the SPSS Version 18.0 (SPSS Inc., Chicago, IL, USA). Quantitative data were expressed as mean $\pm \mathrm{SD}$, and qualitative data were expressed as frequency and percentage. Independent samples $t$-test of significance was used when comparing two means, receiver operating characteristic (ROC) curve analysis was used to find the overall predictivity of parameters and the best cutoff value for detection, along with sensitivity and specificity, and univariate analysis was performed for each variable followed by multivariate analysis to detect factors' predictors for poor survival. The Mann-Whitney $U$-test was used to compare two nonparametric quantitative variables. Survival curve analysis was carried out to detect the probability of survival according to VEGF and endocan levels among HCC group and the prognostic values, and $P<0.05$ was considered statistically significant.

\section{Results}

No statistically significant difference was observed between studied groups as regard age $(P=0.28)$ and gender $(P=0.46)$, the mean age was higher in the cirrhotic group (57.3 \pm 13.5$)$

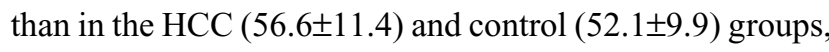
and the majority of studied patients were males in all years.

The mean serum level of endocan and VEGF shows a highly statistically significant increase in the $\mathrm{HCC}$ group than in the cirrhotic without $\mathrm{HCC}$ and control groups $(P<0.001)$ (Table 1). The mean endocan level was higher in the ChildPugh score (C) than in the Child-Pugh scores (A) and (B) among the HCC group. VEGF was higher in the Child-Pugh score (A) than in the Child-Pugh scores (C) and (B) among HCC groups but without statistical significance $(P=0.13)$.

Also, endocan was higher in the Child-Pugh score (C) than in the Child-Pugh scores (A) and (B) among the Cirrhotic group. VEGF was higher in the Child-Pugh score (B) than in the Child-Pugh scores (A) and (C) among Cirrhotic groups without a statistically significant difference $(P=0.056)$ (Table 2).

There are a highly statistically significant positive correlation between serum endocan level and serum bilirubin, ALT, ALP, PT, AFP, and focal lesion (tumor size and number) and severity of liver disease as regard by both Child-Pugh and MELD scores, a significant negative correlation with

Table I Comparison between studied groups as regard mean serum level of endocan and VEGF

\begin{tabular}{|c|c|c|c|c|c|}
\hline Variables & $\begin{array}{l}\text { Group I } \\
\text { Cirrhosis with } \\
\text { HCC }(\mathrm{N}=105)\end{array}$ & $\begin{array}{l}\text { Group II } \\
\text { Cirrhosis without } \\
\text { HCC }(\mathrm{N}=90)\end{array}$ & $\begin{array}{l}\text { Group III } \\
\text { Control }(\mathrm{N}=60)\end{array}$ & $\begin{array}{l}\text { Test } \\
\text { (KWT) }\end{array}$ & $P$-value \\
\hline Endocan $(\mathrm{pg} / \mathrm{mL})$, mean $\pm \mathrm{SD}$ (range) & $\begin{array}{l}\text { a,b } 4,257.6 \pm 847.6 \\
(3,145.0-5,708.0)\end{array}$ & $\begin{array}{l}\text { a2,099..459.6 } \\
(1,371.0-2,789.0)\end{array}$ & $\begin{array}{l}412.6 \pm 176.6 \\
(135.6-854.5)\end{array}$ & 206.1 & $<0.001$ (HS) \\
\hline $\operatorname{VEGF}(\mathrm{pg} / \mathrm{mL})$, mean $\pm \mathrm{SD}$ (range) & $\begin{array}{l}\text { a2, } 180.8 \pm 1,621.4 \\
(621.0-5,104.0)\end{array}$ & $\begin{array}{l}\text { a। }, 605.3 \pm 4,082.4 \\
(58.0-22,344.0)\end{array}$ & $\begin{array}{l}561.0 \pm 251.7 \\
(225.9-1,098.0)\end{array}$ & 75.6 & $<0.00 \mathrm{I}$ (HS) \\
\hline
\end{tabular}

Notes: a Significant in comparison with controls. ${ }^{b}$ Significant in comparison with cirrhosis without HCC. The bold values indicate highly statistical significance. Abbreviations: HCC, hepatocellular carcinoma; HS, highly significant; KWT, Kruskal-Wallis test; VEGF, vascular endothelial growth factor. 
$\mathrm{Hb}$, platelets and albumin, and an insignificant negative correlation with VEGF in the HCC group, while in the cirrhotic group without HCC, endocan level was significantly positively correlated with PT, MELD, AST, T. bilirubin and Child-Pugh scores. The serum level of VEGF was insignificantly negatively correlated with the serum level of AFP and positively correlated with albumin, negatively correlated with WBCs, PT and Child score in HCC group (Table 3).

Endocan at the cutoff value of $2,967 \mathrm{pg} / \mathrm{mL}$ had higher sensitivity (97.1\%) and higher specificity (96.7\%) than AFP (sensitivity [91.4\%] and specificity [90\%]) and VEGF (sensi- tivity [60\%] and specificity [56.7\%]) in the diagnosis of HCC with AUC 0.951 (Figure 1). After 9 months of follow-up, 15 cases of HCC group (14.3\%) and 18 cases of cirrhosis without HCC group (20\%) died. Survival curve analysis for the probability of survival according to VEGF and endocan levels was carried out in the HCC group and detected that the survival in HCC patients with very high levels of VEGF and endocan $(>4,000 \mathrm{pg} / \mathrm{mL})$ were significantly lower than that in HCC patients with low levels of two markers $(P=0.04$ for endocan and $P=0.001$ for VEGF), confirming their role as prognostic markers for survival in HCC patients (Figure 2).

Table 2 Endocan and VEGF levels according to Child-Pugh score among HCC group and cirrhosis group Table 2 Endocan and VEGF levels according to Child-Pugh score among HCC group and cirrhosis group

\begin{tabular}{|c|c|c|c|c|c|c|c|c|c|c|c|}
\hline \multirow{2}{*}{$\begin{array}{l}\text { Child- } \\
\text { Pugh }\end{array}$} & \multirow[t]{2}{*}{$\mathbf{n}$} & \multicolumn{4}{|c|}{ Endocan (pg/mL) } & \multirow[t]{2}{*}{ KWT and $P$} & \multicolumn{4}{|c|}{ VEGF (pg/mL) } & \multirow[t]{2}{*}{ KWT and $F$} \\
\hline & & Mean & \pm SD & Minimum & Maximum & & Mean & \pm SD & Minimum & Maximum & \\
\hline \multicolumn{12}{|c|}{ Endocane and VEGF levels according to Child-Pugh score among HCC group } \\
\hline A & 45 & 3396.0 & 223.3 & 3145.0 & 3840.0 & 78.4 and $<0.001$ & 2605.6 & 1772.2 & $7 \mid 4.6$ & 4825.0 & 3.98 and 0.13 \\
\hline B & 39 & $4333.6 *$ & 888.7 & 1432.0 & 4785.0 & $(\mathrm{HS})$ & 2091.3 & 1573.4 & 621.0 & 5104.0 & \\
\hline C & 21 & $5486.2^{* \wedge}$ & 181.6 & 5175.0 & 5708.0 & & 1436.7 & 1226.3 & 749.4 & 4105.0 & \\
\hline \multicolumn{12}{|c|}{ Endocan and VEGF levels according to Child-Pugh score among cirrhosis group. } \\
\hline A & 3 & 1516.0 & 0.0 & 1516.0 & 1516.0 & 38.1 and $<0.001$ & 488.0 & - & 488.0 & 488.0 & 5.76 and \\
\hline B & 27 & 1869.4 & 1056.1 & 4768.0 & 4768.0 & $(\mathrm{HS})$ & 3694.6 & 6777.1 & 58.0 & 22344.0 & 0.056 (NS) \\
\hline C & 60 & $2398.5^{* \wedge}$ & 164.0 & 2789.0 & 2789.0 & & 3510.8 & 6482.6 & 263.0 & 22344.0 & \\
\hline
\end{tabular}

Notes: *Significant in comparison with A, ^Significant in comparison with B.

Abbreviations: HCC, hepatocellular carcinoma; HS, highly significant; KWT, Kruskal-Wallis test; VEGF, vascular endothelial growth factor.

Table 3 Correlation between serum Endocan and VEGF level and some studied variables among patients groups (Group I, II)

\begin{tabular}{|c|c|c|c|c|c|c|c|c|}
\hline \multirow[t]{3}{*}{ Variable } & \multicolumn{4}{|c|}{ Serum endocan } & \multicolumn{4}{|c|}{ Serum VEGF } \\
\hline & \multicolumn{2}{|c|}{$\begin{array}{l}\text { Cirrhosis with HCC } \\
(\mathrm{N}=105)\end{array}$} & \multicolumn{2}{|c|}{$\begin{array}{l}\text { Cirrhosis without HCC } \\
(\mathrm{N}=90)\end{array}$} & \multicolumn{2}{|c|}{$\begin{array}{l}\text { Cirrhosis with HCC } \\
(\mathrm{N}=105)\end{array}$} & \multicolumn{2}{|c|}{$\begin{array}{l}\text { Cirrhosis without } \mathrm{HCC} \\
(\mathrm{N}=90)\end{array}$} \\
\hline & Rho & $P$ & Rho & $P$ & Rho & $P$ & Rho & $P$ \\
\hline Age & 0.105 & 0.28 & -0.066 & 0.53 & -0.061 & 0.53 & 0.199 & 0.06 \\
\hline $\mathrm{Hb}(\mathrm{gm} / \mathrm{dl})$ & -0.419 & $<0.00 \mathrm{I}(\mathrm{HS})$ & 0.097 & 0.38 & 0.004 & 0.96 & 0.048 & 0.65 \\
\hline WBCs $\left(\mathbf{c} / \mathbf{m m}^{3}\right)$ & 0.340 & $<0.001$ (HS) & 0.179 & 0.09 & -0.293 & $0.002(S)$ & -0.104 & 0.33 \\
\hline PLTs $\left(\mathrm{c} / \mathrm{mm}^{3}\right)$ & -0.217 & $0.026(\mathrm{~S})$ & -0.07 & 0.52 & 0.059 & 0.55 & 0.035 & 0.74 \\
\hline ALT (U/I) & 0.259 & $0.008(S)$ & 0.193 & 0.064 & 0.037 & 0.71 & -0.058 & 0.56 \\
\hline AST(U/I) & 0.164 & 0.094 & 0.239 & $0.024(\mathrm{~S})$ & 0.121 & 0.22 & 0.022 & 0.83 \\
\hline T. bilirubin (mg/dl) & 0.626 & $<0.001$ & 0.295 & $0.005(\mathrm{~S})$ & -0.095 & 0.33 & 0.021 & 0.84 \\
\hline D. bilirubin ( $\mathrm{mg} / \mathrm{dl})$ & $0.65 \mathrm{I}$ & $<0.001$ & 0.107 & 0.31 & -0.077 & 0.43 & -0.068 & 0.52 \\
\hline Albumin (gm/dl) & -0.552 & $<0.001$ & -0.017 & 0.87 & 0.234 & $0.016(S)$ & -0.009 & 0.93 \\
\hline ALP (u/l) & 0.300 & $0.002(\mathrm{~S})$ & -0.030 & 0.78 & 0.023 & 0.82 & 0.193 & 0.068 \\
\hline PT (/ sec) & 0.464 & $<0.00 \mathrm{I}(\mathrm{HS})$ & 0.409 & $<0.00 \mathrm{I}$ (HS) & -0.201 & $0.039(\mathrm{~S})$ & 0.157 & 0.14 \\
\hline INR & 0.180 & 0.103 & 0.245 & $0.02(\mathrm{~S})$ & -0.318 & 0.063 & 0.164 & 0.12 \\
\hline Creatinine (mg/dl) & 0.164 & 0.086 & -0.085 & 0.42 & 0.061 & 0.73 & -0.012 & 0.92 \\
\hline AFP (ng/dl) & 0.490 & $<0.00 \mathrm{I}(\mathrm{HS})$ & -0.123 & 0.25 & -0.101 & 0.29 & -0.160 & 0.39 \\
\hline VEGF( pg/ml) & -0.178 & 0.09 & 0.158 & 0.13 & - & - & - & - \\
\hline T size & 0.700 & $<0.001$ & - & - & -0.177 & 0.071 & - & - \\
\hline T number & 0.841 & $<0.001$ & - & - & -0.265 & $0.006(\mathrm{~S})$ & - & - \\
\hline Stage & 0.623 & $<0.001$ & 0.308 & $0.003(S)$ & 0.01 & 0.92 & 0.046 & 0.66 \\
\hline Chid-Pugh score & 0.866 & $<0.001$ & 0.653 & $<0.001$ & -0.195 & $0.046(\mathrm{~S})$ & 0.039 & 0.71 \\
\hline MELD & 0.607 & $<0.001$ & 0.381 & $<0.001$ & -0.168 & 0.087 & -0.062 & 0.55 \\
\hline
\end{tabular}

Abbreviations: AFP, $\langle$-fetoprotein; ALT, alanine aminotransferase; AST, aspartate aminotransferase; HCC, hepatocellular carcinoma; $\mathrm{HS}$, highly significant; INR, international normalized ratio; MELD, Model for End-stage Liver Disease; S, significant; VEGF, vascular endothelial growth factor. 


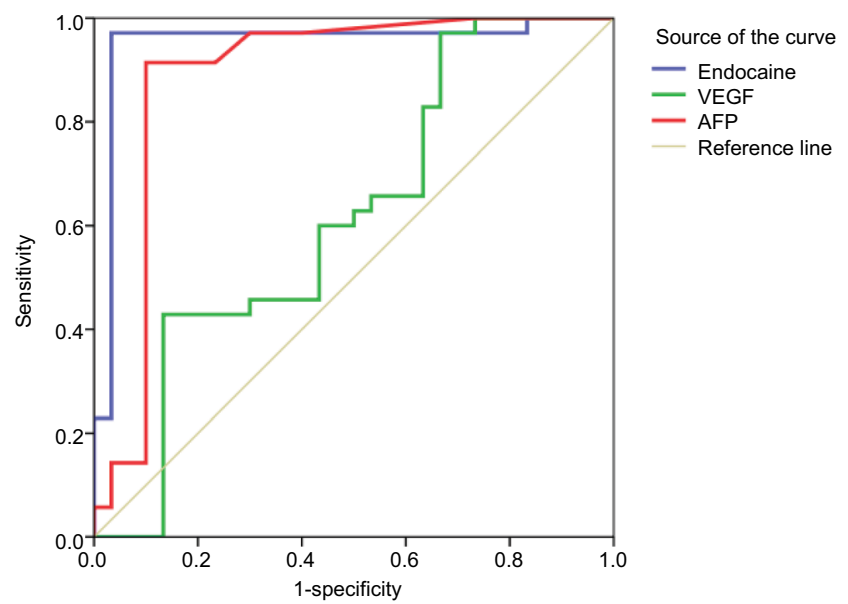

Figure I ROC curve for the performance of endocan, VEGF, and AFP in the diagnosis of HCC.

Abbreviations: AFP, $\alpha$-fetoprotein; HCC, hepatocellular carcinoma; VEGF, vascular endothelial growth factor.

Using univariate and multivariate analyses, the study found that tumour size, $\operatorname{AFP}(>100 \mathrm{ng} / \mathrm{dL})$ and endocan $(\geq 4,000 \mathrm{pg} /$ $\mathrm{mL}$ ) were significant independent predictors of mortality in HCC group and the combination of the elevated levels of AFP, endocan, and VEGF also increased the risk of mortality (Table 4).

\section{Discussion}

$\mathrm{HCC}$ is a standout amongst the most exceptionally dangerous and deadly malignancies. Its pathogenesis has been accounted for to be multifactorial, what's more, the molecular carcinogenesis of HCC can't be credited to only a couple of individual genes.15 Early identification of patients with HCC is appealing in light of the fact that it gives a superior forecast as HCC has a tendency to develop gradually and remain restricted to the liver. Early recognition is conceivable with ultrasound examining also, AFP checking, in spite of the fact that the utilization of AFP as a screening test is inadmissible as a result of the regular false-positive and false-negative results. 16 Hence, there is a squeezing requirement for the assurance of new serological markers with adequate specificity and affectability utilized in the determination of HCC. The point of this examination was to decide the serum endocan and VEGF levels in the patients with HCC in correlation with its levels in the patients with cirrhosis and control and to distinguish its value as a diagnostic biomarker for $\mathrm{HCC}$ and if we can utilize it as predictors of mortality.

In the current study, there was statistically highly significant elevation $(P<0.01)$ in the mean serum AFP in the HCC group $(717.7 \mathrm{ng} / \mathrm{dL})$ when compared with the cirrhotic group $(6.33 \mathrm{ng} / \mathrm{mL})$ and this was not in agreement with a study done by Massironi et a $\mathrm{l}^{17}$ who reported no significant difference in AFP between HCC and liver cirrhosis subjects. In our study, considering the cutoff value of $10.2 \mathrm{ng} / \mathrm{dL}$, the sensitivity of AFP was $91.4 \%$ and the specificity was $90 \%$. These results were similar with the results of study by Massironi et al ${ }^{17}$ and Metwaly et al, ${ }^{18}$ who reported a sensitivity of $75 \%$ and a specificity of $80 \%$ at cutoff $16.9 \mathrm{ng} / \mathrm{dL}$.

In the current study, the mean serum endocan levels were higher in HCC patients than in non-HCC patients, which was in agreement with the results of previous studies by Ozaki et $\mathrm{al}^{4}$ and Nault et al. ${ }^{19}$

In this study, there were a highly statistically significant positive correlation between serum endocan level and serum bilirubin (T and D), ALT, ALP, PT, AFP, and focal lesion (tumor size and number) and severity of liver disease using both Child-Pugh and MELD scores, a significant negative correlation with $\mathrm{Hb}$, platelets and albumin, and an insignificant negative correlation with VEGF $(\mathrm{Rho}=-0.178, \mathrm{P}=0.09)$ in the $\mathrm{HCC}$ group, while in the cirrhotic group without $\mathrm{HCC}$, endocan level was significantly positively correlated with PT AST, bilirubin and MELD and Child-Pugh scores, which coincided with the study by Ozaki et al, ${ }^{4}$ who detailed that serum endocan levels were not related with age, sexual orientation, or etiology of liver sickness however were decidedly related with the Child- Pugh review in HCC patients also, higher number of tumors demonstrating a nearby connection between serum endocan level and HCC aggressiveness.

In the present study, endocan at best cutoff values $(2,967 \mathrm{pg} / \mathrm{mL})$ had higher sensitivity $(97.7 \%)$ and higher specificity (96.7\%) than AFP and VEGF with area under the curve $0.951(95 \% \mathrm{CI}=0.88-0.1, P<0.001)$.

In the present study, serum level of VEGF was higher in the HCC group than in the cirrhotic and control groups with a higher statistically significant difference $(P<0.001)$, which was in agreement with the study Atta et $\mathrm{al}^{20}{ }^{20}$ who reported that plasma VEGF was higher in the HCC group $(488.40 \pm 139.0 \mathrm{pg} /$ $\mathrm{mL})$ than in the non-HCC group $(197.93 \pm 50.3 \mathrm{pg} / \mathrm{mL})$, and both groups had significantly higher VEGF levels compared to control group $(134.13 \pm 51.94 \mathrm{pg} / \mathrm{mL})(P<0.001)$.

In the present study, serum VEGF levels were not significantly correlated with MELD score, ALT levels, and bilirubin levels, international normalized ratio (INR), or Okuda stage in the HCC patients, which was in agreement with the study by Atta et al, ${ }^{20}$ who announced that VEGF was not altogether related with MELD score. Besides, serum VEGF levels were not correlated with ALT levels, serum bilirubin, or INR among HCC gatherings. Moreover, plasma VEGF levels were not correlated with Okuda ( $r=0.01, P=0.92)$. 
A

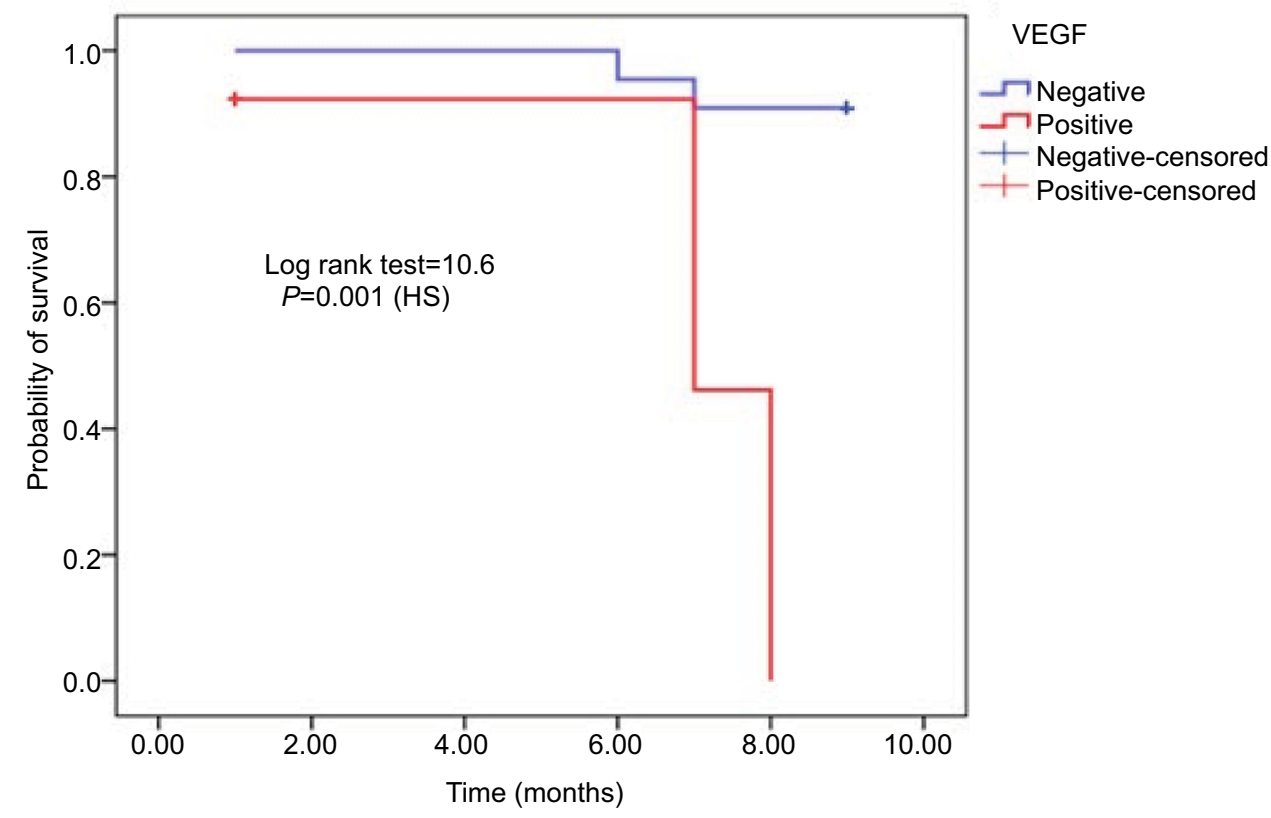

B

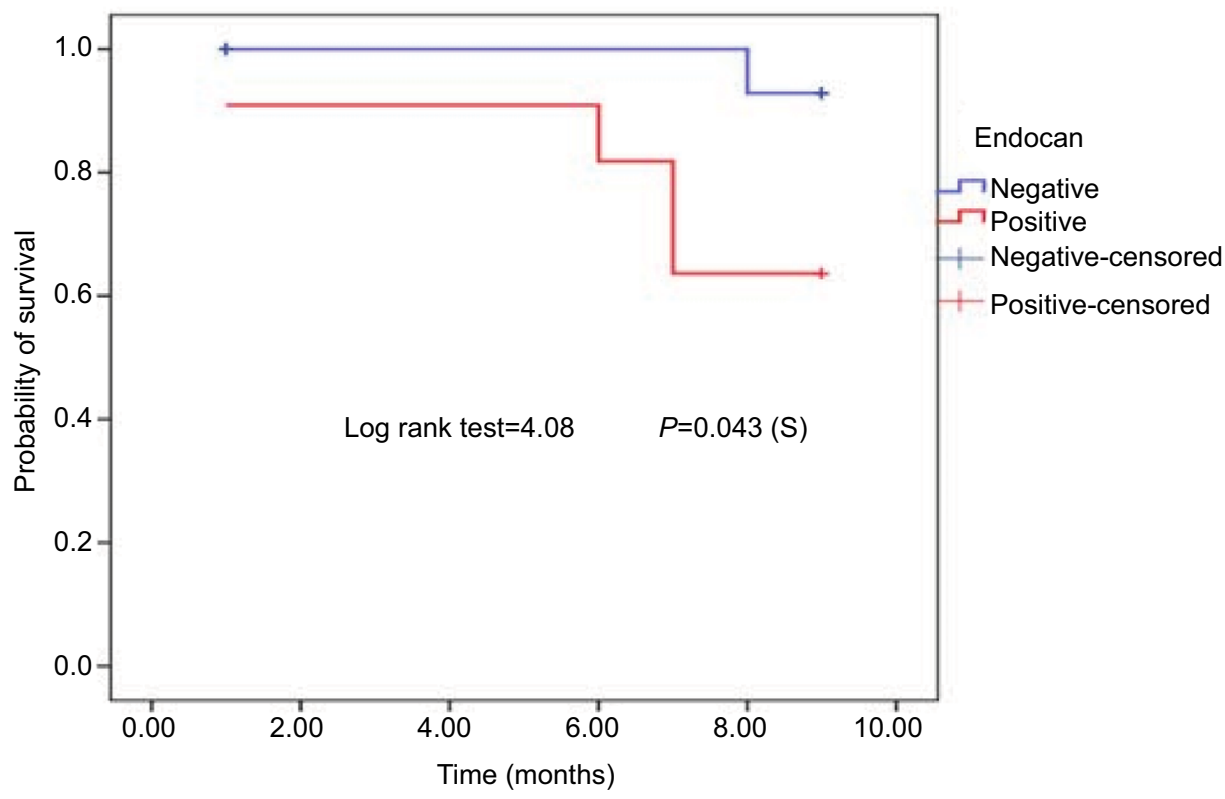

Figure 2 Kaplan Meier curve for the probability of survival according to: (A) VEGF level among HCC group. (B) endocan level among HCC group.

Also, in the present study, the serum VEGF level was not significantly correlated with the size of HCC focal lesions, which was in agreement with the studies by Poon et $\mathrm{al}^{21}$ and EL-Hosseini et al. ${ }^{22}$ However, Tseng et $\mathrm{al}^{23}$ and Sergio et $\mathrm{al}^{24}$ reported a significant positive correlation between plasma VEGF levels and the size of HCC focal lesions; this difference may relate to different ethnic population of patients in our study. The current study found that the plasma VEGF level at cutoff value $961.0 \mathrm{pg} / \mathrm{mL}$ had much lower sensitivity (60\%) and specificity (56.7\%) with AUC (0.6) than both AFP and endocan levels in the diagnosis of HCC that was disagreed with results of Nassar et al, ${ }^{25}$ who showed that the diagnostic value of HCC-VEGF was analyzed by the ROC curve showing an AUC of 0.9706. In this study, the sensitivity $(100 \%)$ and specificity $(82.86 \%)$ for HCC-VEGF were at a cutoff value of $2.59 \mathrm{pg} / \mathrm{mL}$ for the discrimination of patients 
Table 4 Univariate and multivariate logistic regression analysis for the predictors of mortality among HCC group

\begin{tabular}{|c|c|c|c|c|c|c|}
\hline \multicolumn{2}{|l|}{ Variable } & \multirow{3}{*}{\begin{tabular}{|l|} 
No. \\
45 \\
\end{tabular}} & \multicolumn{2}{|l|}{ Univariate } & \multicolumn{2}{|c|}{$\begin{array}{l}\text { Multivariate logistic } \\
\text { regression }\end{array}$} \\
\hline & & & OR (95\% Cl) & $\mathbf{P}$ & OR (95\% Cl) & $\mathbf{P}$ \\
\hline \multirow[t]{2}{*}{ Child-Pugh } & $A$ & & \multicolumn{2}{|c|}{$\mathrm{R}$} & & \\
\hline & $\mathrm{B} / \mathrm{C}$ & 60 & $3.5(0.92-13.5)$ & 0.053 & - & - \\
\hline \multirow[t]{2}{*}{ MELD } & $\leq 38$ & 72 & \multicolumn{2}{|c|}{$R$} & & \\
\hline & $>38$ & 33 & $1.56(0.5-4.8)$ & 0.55 & - & - \\
\hline \multirow[t]{2}{*}{ AFP (ng/dl) } & $<100$ & 75 & \multicolumn{2}{|c|}{$R$} & & \\
\hline & $>100$ & 30 & $16(4.1-62.7)$ & $<0.00$ I(HS) & $9.62(2.2-4 \mid .8)$ & $0.003(\mathrm{~S})$ \\
\hline \multirow[t]{2}{*}{ Endocan (pg/ml) } & $<4000$ & 72 & \multicolumn{2}{|c|}{$\mathbf{R}$} & & \\
\hline & $\geq 4000$ & 33 & I3.I (3.3-5I.0) & $<0.00$ I(HS) & $8.5(1.8-30.8)$ & $0.017(\mathrm{~S})$ \\
\hline \multirow[t]{2}{*}{ VEGF (pg/dl) } & $<2906$ & 66 & \multicolumn{2}{|r|}{$\mathrm{R}$} & & \\
\hline & $\geq 2906$ & 39 & $3(0.98-9.2)$ & 0.08 & - & - \\
\hline \multirow{2}{*}{ Okuda staging } & $\mathrm{I} / \mathrm{II}$ & 87 & \multicolumn{2}{|c|}{$\mathrm{R}$} & & \\
\hline & III/IV & 18 & $1.3(0.31-4.97)$ & 0.72 & - & - \\
\hline \multirow[t]{2}{*}{ Size $(\mathrm{cm})$} & $\leq 3 \mathrm{~cm}$ & 51 & \multicolumn{2}{|c|}{$\mathrm{R}$} & & \\
\hline & $>3 \mathrm{~cm}$ & 54 & $4.6(1.2-17.3)$ & $0.017(\mathrm{~S})$ & $2.34(1.2-6.5)$ & $0.024(\mathrm{~S})$ \\
\hline \multirow[t]{2}{*}{ T number } & Single & 48 & \multicolumn{2}{|c|}{$\mathrm{R}$} & & \\
\hline & Multiple & 57 & $1.3(0.43-3.99)$ & 0.78 & - & - \\
\hline \multirow[t]{2}{*}{ AFP-Endocan } & $0 / 1$ & 87 & \multicolumn{2}{|c|}{$\mathbf{R}$} & \multicolumn{2}{|c|}{$\mathrm{R}$} \\
\hline & 2 & 18 & $35(6.9-68.5)$ & $<0.00 \mathrm{I}(\mathrm{HS})$ & $27.4(1.9-44.5)$ & $0.023(\mathrm{~S})$ \\
\hline \multirow[t]{2}{*}{ AFP-VEGF } & $0 / 1$ & 93 & \multicolumn{2}{|c|}{$\mathbf{R}$} & \multicolumn{2}{|c|}{$\mathbf{R}$} \\
\hline & 2 & 12 & $23.5(5.1-63.2)$ & 0.001 (HS) & I3.8 (2.5-50.I) & $0.013(\mathrm{~S})$ \\
\hline \multirow[t]{2}{*}{ AFP-Endocan-VEGF } & $0 / 1$ & 87 & \multicolumn{2}{|r|}{$\mathbf{R}$} & \multicolumn{2}{|l|}{$\mathbf{R}$} \\
\hline & $2 / 3$ & 18 & $35(6.9-68.5)$ & $<0.00 \mathrm{I}$ (HS) & $27.4(1.9-44.5)$ & $0.023(\mathrm{~S})$ \\
\hline
\end{tabular}

Note: The bold values represent significant values.

Abbreviations: AFP, 〈-fetoprotein; HCC, hepatocellular carcinoma; HS, highly significant; MELD, Model for End-stage Liver Disease; R, reference; S, significant; VEGF, vascular endothelial growth factor.

with HCC from those with liver cirrhosis. Similar findings were obtained by El-Mezayen et al ${ }^{26}$ who announced that the AUC for VEGF for segregating HCC patients from liver cirrhosis was 0.98 with an sensitivity of $91 \%$ and a specificity of $82 \%$ at cutoff 4.4 . Likewise, Atta et $\mathrm{al}^{20}$ found that the ideal cutoff esteem of plasma VEGF for diagnosing HCC was $271.85 \mathrm{pg} / \mathrm{mL}$ with an sensitivity of $90 \%$, a specificity of $90 \%$, a precision of $87.3 \%$, of $88.1 \%$ (AUC $=0.97$ ). In the present study, the result of univariate and multivariate analyses for the detection of independent risk factors for mortality in HCC patients revealed that AFP (>100 ng/dL) and endocan $(>4,000 \mathrm{pg} / \mathrm{mL})$ were significant independent predictors for mortality in the HCC group and also the combination of elevated level of AFP, endocan, and VEGF increased the risk of mortality; no literature was discussed about this point. Survival curve analysis for the probability of survival according to VEGF and endocan levels was carried out among HCC group and detected that the survival in HCC patients with high levels of VEGF and endocan $(>4,000 \mathrm{pg} /$ $\mathrm{mL}$ ) was significantly lower than that in $\mathrm{HCC}$ patients with low levels of two markers ( $P=0.04$ for endocan and 0.001 for VEGF) (Figure 2).

\section{Conclusion}

Serum level of endocan can be considered as good biomarker for the diagnosis of HCC, and its higher level can be used as a possible prediction for mortality in $\mathrm{HCC}$ patients

\section{Informed consent}

Informed consent was obtained from all individual participants included in the study.

\section{Author contributions}

AAY, HAI, and EGB substantially contributed to the conception and design of the work and acquisition of data, drafted the work, contributed to the final approval of the version published, and agreed all aspects of the work in ensuring that questions related to the accuracy or integrity of any part of the work are appropriately investigated and resolved, to be accountable. HAI, MZO, EGB, and DBI contributed to the statistical analysis and interpretation of data, drafted the work and revised it critically for important intellectual content, contributed to the final approval of the version published, and agreed all aspects of the work in ensuring that questions related to the accuracy or integrity of any part of the work 
are appropriately investigated, to be accountable. All authors contributed to data analysis, drafting or revising the article, gave final approval of the version to be published, and agree to be accountable for all aspects of the work.

\section{Disclosure}

The authors report no conflicts of interest in this work.

\section{References}

1. Venepalli NK, Goff L, Venepalli NK, Goff L. Targeting the HGF-cMET axis in hepatocellular carcinoma. Int J Hepatol. 2013;2013:1-11.

2. Holah NS, El-Azab DS, Aiad HA, Sweed DM. Hepatocellular carcinoma in Egypt: epidemiological and histopathological properties. Menoufia Med J. 2015;28(3):718.

3. Moftah WSM. Clinical Utility of Alfa-F etoprotein-L3 in Hepatocellalar Carcinoma Patients [Doctoral Dissertation]. Benha University. 2012;1:6-12.

4. Ozaki K, Toshikuni N, George J, et al. Serum endocan as a novel prognostic biomarker in patients with hepatocellular carcinoma. J Cancer. 2014;5(3):221-230.

5. Abid MR, Yi X, Yano K, Shih SC, Aird WC. Vascular endocan is preferentially expressed in tumor endothelium. Microvasc Res. 2006;72(3):136-145.

6. Rennel E, Mellberg S, Dimberg A, et al. Endocan is a VEGF-A and $\mathrm{PI} 3 \mathrm{~K}$ regulated gene with increased expression in human renal cancer. Exp Cell Res. 2007;313(7):1285-1294.

7. Maurage CA, Adam E, Minéo JF, et al. Endocan expression and localization in human glioblastomas. $J$ Neuropathol Exp Neurol. 2009;68(6):633-641.

8. Abdel-Haleem H, El Kateb S, Gohar N, Hamdy E. Evaluation of the diagnostic and prognostic value of AFP, PIVKA-II, VEGF and TGF- $\beta 1$ in the diagnosis and follow up of patients with hepatocellular carcinoma. Arab J Gastroenterol. 2007;8(3):84-89.

9. Yamaguchi R, Yano H, Nakashima Y, et al. Expression and localization of vascular endothelial growth factor receptors in human hepatocellular carcinoma and non-HCC tissues. Oncol Rep. 2000;7(4):725-734.

10. Fontanini G, Vignati S, Boldrini L, et al. Vascular endothelial growth factor is associated with neovascularization and influences progression of non-small cell lung carcinoma. Clin Cancer Res. 1997;3(6): 861-865.

11. European Association For The Study Of The Liver, European Organisation For Research And Treatment Of Cancer. EASL-EORTC clinical practice guidelines: management of hepatocellular carcinoma. $J$ Hepatol. 2012;56(4):908-943.
12. Pugh RN, Murray-Lyon IM, Dawson JL, Pietroni MC, Williams R. Transection of the oesophagus for bleeding oesophageal varices. $\mathrm{Br} J$ Surg. 1973;60(8):646-649.

13. Kamath PS, Kim WR. The model for end-stage liver disease (MELD). Hepatology. 2007;45(3):797-805.

14. Okuda K, Ohtsuki T, Obata H, et al. Natural history of hepatocellular carcinoma and prognosis in relation to treatment. Study of 850 patients. Cancer. 1985;56(4):918-928.

15. Wei L, Lian B, Zhang Y, et al. Application of microRNA and mRNA expression profiling on prognostic biomarker discovery for hepatocellular carcinoma. BMC Genomics. 2014;15 Suppl 1(1):S13.

16. Gogel BM, Goldstein RM, Kuhn JA, Mccarty TM, Donahoe A, Glastad K. Diagnostic evaluation of hepatocellular carcinoma in a cirrhotic liver14(6). OncologySUPP/. 2000;3:15-20.

17. Massironi S, Fraquelli M, Paggi S, et al. Chromogranin A levels in chronic liver disease and hepatocellular carcinoma. Dig Liver Dis. 2009;41(1): 31-35.

18. Metwaly K, Sameea EA, El-Azab G, et al. Mean platelet volume and mean platelet volume/platelet count ratio as markers for hepatocellular carcinoma in patients with chronic hepatitis $\mathrm{C}$ virus related cirrhosis. J Cancer Res Clin Onco. 2016;8(4):33-40.

19. Nault JC, Guyot E, Laguillier C, et al. Serum proteoglycans as prognostic biomarkers of hepatocellular carcinoma in patients with alcoholic cirrhosis. Cancer Epidemiol Biomarkers Prev. 2013;22(8):0179-1352.

20. Atta MM, El-Masry SA, Abdel-Hameed M, Baiomy HA, Ramadan NE. Value of serum anti-p53 antibodies as a prognostic factor in Egyptian patients with hepatocellular carcinoma. Clin Biochem. 2008;41(14-15):1131-1139

21. Poon RT, Ng IO, Lau C, et al. Serum vascular endothelial growth factor predicts venous invasion in hepatocellular carcinoma: a prospective study. Ann Surg. 2001;233(2):227-235.

22. El-Houseini ME, Mohammed MS, Elshemey WM, Hussein TD, Desouky OS, Elsayed AA. Enhanced detection of hepatocellular carcinoma. Cancer Control. 2005;12(4):248-253.

23. Tseng CS, Lo HW, Chen PH, Chuang WL, Juan CC, Ker CG. Clinical significance of plasma D-dimer levels and serum VEGF levels in patients with hepatocellular carcinoma. Hepatogastroenterology. 2004;51(59):1454-1458

24. Sergio A, Cristofori C, Cardin R, et al. Transcatheter arterial chemoembolization (TACE) in hepatocellular carcinoma (HCC): the role of angiogenesis and invasiveness. Am J Gastroenterol. 2008;103(4):914-921.

25. Nassar AK, Abd El-Raouf HS, Ahmed ES, Abd El-Baky HR, AbdelHamid MS. Evaluation of hepatocellular carcinoma-vascular growth factor score for any detection of hepatocellular carcinoma among hepatitis C virus patients. Int J Adv Res. 2016;4(2):322-338.

26. El-Mezayen HA, Darwish H. Development of a novel score for early detection of hepatocellular carcinoma among high-risk hepatitis $C$ virus patients. Tumour Biol. 2014;35(7):6501-6509.
Clinical and Experimental Gastroenterology

\section{Publish your work in this journal}

Clinical and Experimental Gastroenterology is an international, peerreviewed, open access, online journal publishing original research, reports, editorials, reviews and commentaries on all aspects of gastroenterology in the clinic and laboratory. This journal is included on PubMed. The manuscript management system is completely online

\section{Dovepress}

and includes a very quick and fair peer-review system, which is all easy to use. Visit http://www.dovepress.com/testimonials.php to read real quotes from published authors. 